Article

\title{
The Possible Role of the Nitroso-Sulfide Signaling Pathway in the Vasomotoric Effect of Garlic Juice
}

\author{
Andrea Berenyiova ${ }^{1, *}$, Marian Grman ${ }^{2}{ }^{\mathbb{D}}$, Anton Misak ${ }^{2}$, Samuel Golas ${ }^{1}$, Justina Cuchorova ${ }^{3}$ \\ and Sona Cacanyiova ${ }^{1}$ \\ 1 Institute of Normal and Pathological Physiology, Centre of Experimental Medicine, Slovak Academy of \\ Sciences,841 04 Bratislava, Slovakia; samuel.golas@savba.sk (S.G.); sona.cacanyiova@savba.sk (S.C.) \\ 2 Institute for Clinical and Translational Research, Biomedical Research Center, Slovak Academy of Sciences, \\ 84505 Bratislava, Slovakia; marian.grman@savba.sk (M.G.); anton.misak@savba.sk (A.M.) \\ 3 Axxence Slovakia, Ltd., 81107 Bratislava, Slovakia; justina.cuchorova@axxence.sk \\ * Correspondence: andrea.berenyiova@savba.sk
}

Academic Editors: Olga Pecháňová and Martina Cebova

Received: 13 December 2019; Accepted: 27 January 2020; Published: 29 January 2020

check for updates

\begin{abstract}
The beneficial cardiovascular effects of garlic have been reported in numerous studies. The major bioactive properties of garlic are related to organic sulfides. This study aimed to investigate whether garlic juice works exclusively due to its sulfur compounds or rather via the formation of new products of the nitroso-sulfide signaling pathway. Changes in isometric tension were measured on the precontracted aortic rings of adult normotensive Wistar rats. We evaluated NO-donor (S-nitrosoglutathione, GSNO)-induced vasorelaxation and compare it with effects of hydrogen sulfide $\left(\mathrm{H}_{2} \mathrm{~S}\right) / \mathrm{GSNO}$ and garlic/GSNO. Incubation with garlic juice increased the maximal GSNO-induced relaxation and markedly changed the character of the relaxant response. Although incubation with an $\mathrm{H}_{2} \mathrm{~S}$ donor enhanced the maximal vasorelaxant response of GSNO, neither the absolute nor the relative relaxation changed over time. The mixture of GSNO with an $\mathrm{H}_{2} \mathrm{~S}$ donor evoked a response similar to GSNO-induced relaxation after incubation with garlic juice. This relaxation of the $\mathrm{H}_{2} \mathrm{~S}$ and GSNO mixture was soluble guanylyl cyclase (sGC) dependent, partially reduced by HNO scavenger and it was adenosine triphosphate-sensitive potassium channels $\left(\mathrm{K}_{\mathrm{ATP}}\right)$ independent. In this study, we demonstrate for the first time the suggestion that $\mathrm{H}_{2} \mathrm{~S}$ itself is probably not the crucial bioactive compound of garlic juice but rather potentiates the production of new signaling molecules during the GSNO- $\mathrm{H}_{2} \mathrm{~S}$ interaction.
\end{abstract}

Keywords: garlic; vasoactive mechanisms; $\mathrm{NO}$ donor; $\mathrm{H}_{2} \mathrm{~S}$ donor

\section{Introduction}

The beneficial biological effects of garlic have been well known for a long time; garlic is a commonly used ingredient of traditional medicine worldwide. Recent studies have shown that the bioactive components of garlic provide many biological functions. The bioactive components of garlic are effective antioxidants, immunomodulators and anti-inflammatory, cardiovascular protective, anticancer, hepatoprotective, antidiabetic, anti-obesity, neuroprotective, renal protective, antibacterial and antifungal agents [1-6]. Moreover, it has also been demonstrated that the intake of garlic powder can effectively reduce blood pressure, total cholesterol, low-density lipoprotein cholesterol, and other risk factors of cardiovascular diseases [7]. The major bioactive properties of garlic are related to organic sulfides, such as allicin, alliin, diallyl sulfide, diallyl disulfide, diallyl trisulfide, ajoene and S-allyl-cysteine [8,9]. These bioactive molecules are able to decrease proliferation and migration of the vascular smooth muscle cells, inhibit angiotensin converting enzyme, increase nitric oxide (NO) 
bioavailability and increase hydrogen sulfide $\left(\mathrm{H}_{2} \mathrm{~S}\right)$ production so they can decrease vasoconstriction and enhance vasorelaxation in the arterial bed [10].

Gaseous signal molecules, such as $\mathrm{NO}$ and $\mathrm{H}_{2} \mathrm{~S}$, are endogenously generated by several enzymes and have been demonstrated as influencing a wide range of physiological and pathological processes [11]. Both molecules have been shown to induce several cytoprotective mechanisms that include induction of vasodilatation, inhibition of apoptosis, modulation of mitochondrial respiration, activation of antioxidants, promotion of angiogenesis and inhibition of inflammation [12].

$\mathrm{H}_{2} \mathrm{~S}$ and $\mathrm{H}_{2} \mathrm{~S}$-derived compounds induce potent biological effects due to binding to a metal center of heme proteins or because of post-translational modification of cysteine residues called protein persulfidation (S-sulfhydration); by its interaction with protein disulfides or protein sulfenic acids, $\mathrm{H}_{2} \mathrm{~S}$ can be transported within the organism and released at the target location [13,14]. Similarly, low-molecular-weight thiols bind and transport another important gaseous transmitter, $\mathrm{NO}$ [15]. The cross-talk between $\mathrm{H}_{2} \mathrm{~S}$ and $\mathrm{NO}$ has also been intensively studied [16-21]. The chemical interaction between $\mathrm{H}_{2} \mathrm{~S}$ and $\mathrm{NO}$ is primarily based on the production of nitrosothiols, such as S-nitrosoglutathione (GSNO) [22]. It has been demonstrated that $\mathrm{H}_{2} \mathrm{~S}\left(\mathrm{HS}^{-}\right)$releases $\mathrm{NO}$ from GSNO, potentiating vascular smooth muscle relaxation [16]. Moreover, several other studies have suggested the existence of an interaction between $\mathrm{NO} / \mathrm{H}_{2} \mathrm{~S}$ carriers resulting in the formation of new products [17-20]. These new signaling molecules would trigger quantitatively different vasoactive effects than $\mathrm{NO}$ and $\mathrm{H}_{2} \mathrm{~S}$ alone due to their qualitatively different mechanisms [21]. Recently they are considered to be a part of a new and original nitroso-sulfide signaling pathway. Products of this $\mathrm{H}_{2} \mathrm{~S} / \mathrm{NO}$ interaction appear to have pronounced specific biological effects. The nitroxyl (HNO) is a potential candidate, but several other compounds have been suggested to mediate the bioactivity of the interaction between S-nitrosothiols and $\mathrm{H}_{2} \mathrm{~S}$. For example, thionitrous acid (HSNO) has been proposed [18]. Cortese-Krott et al. [20] observed that sulfide reacted with S-nitrosothiols to form multiple bioactive products and proposed that nitrosopersulfide $\left(\mathrm{SSNO}^{-}\right)$could account for some of the longer-lived effects of the interaction between S-nitrosothiols and $\mathrm{H}_{2} \mathrm{~S}$. However, the nature of the reaction intermediates is still subject of scientific studies.

Recent study has confirmed that garlic extract also interacts with endogenous NO, affects NO production and exerts endothelium-dependent vasorelaxation of the aorta in normotensive rats [23]. This study aims to investigate whether garlic juice or an exogenous $\mathrm{H}_{2} \mathrm{~S}$ donor affects the GSNO-induced vasorelaxation. Another aim of this study is to determine whether garlic extract works exclusively due to its sulfur compounds or rather via the formation of new products related to the nitroso-sulfide signaling pathway.

\section{Results}

\subsection{Gas Chromatography Mass Spectrometric (GC-MS) Analysis of the Garlic Juice}

GC-MS analysis confirmed the presence of several organic sulfur compounds in the garlic juice. (Figure 1). The analysis identified seven major sulfur-containing molecules in the samples. The total molecule chromatogram is showing the peaks for each compound. The samples of garlic juice contained diallyl sulfide, diallyl disulfide and diallyl trisulfide, which are considered to be active compounds with high bioactive properties (see Introduction). 


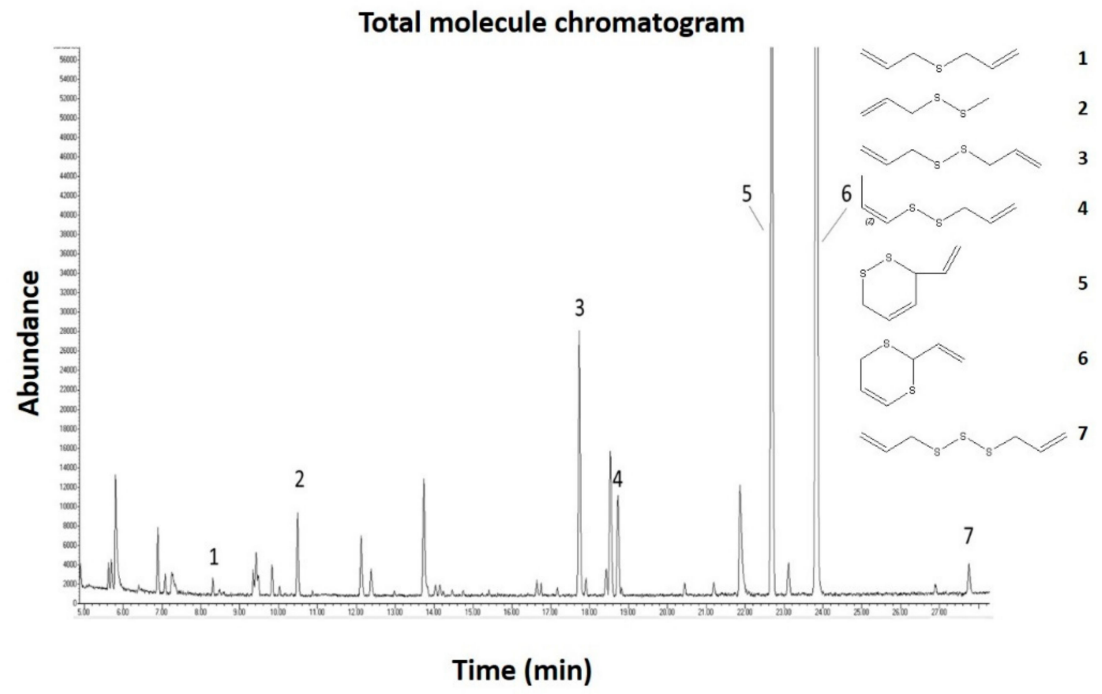

Figure 1. The total molecule chromatogram from gas chromatography mass spectrometric (GC-MS) analysis of the garlic juice. The exact organo-sulfur compounds could be identified and their formula are shown: 1 diallyl sulfide, 2 3-(Methyldisulfanyl)-prop-1-ene, 3 diallyl disulfide, 4 (Z)-1-(prop-2-enyldisulfanyl)prop-1-en, 5 3-ethenyl-3,6- dihydrodithiine, 6 2-ethenyl-4H-1,3-dithiine and 7 diallyl trisulfide.

\subsection{Effect of Garlic Juice Incubation}

A three-minute long incubation with garlic juice $(45 \mathrm{ug} / \mathrm{mL} ; n=9)$ did not affect the vascular tension of the noradrenaline-precontracted aortic rings $(1 \mu \mathrm{M})$ (Figure $2 \mathrm{a})$, however it significantly increased $(p<0.05)$ the maximal GSNO-induced relaxation (Figure 2b). The incubation with the garlic juices markedly changed the character of the GSNO-induced relaxant response. The absolute relaxation was significantly increased at the $1^{\text {st }}$ minute $(p<0.05)$ but reduced at the $3^{\text {rd }}, 4^{\text {th }}$ and $5^{\text {th }}$ min $(p<0.05$; $p<0.01$; Figure 2c). The expression of the relative relaxation over time showed a faster return after incubation with the garlic juice ( $p<0.05 ; p<0.01 ; p<0.001$; Figure $2 \mathrm{~d}$ ).

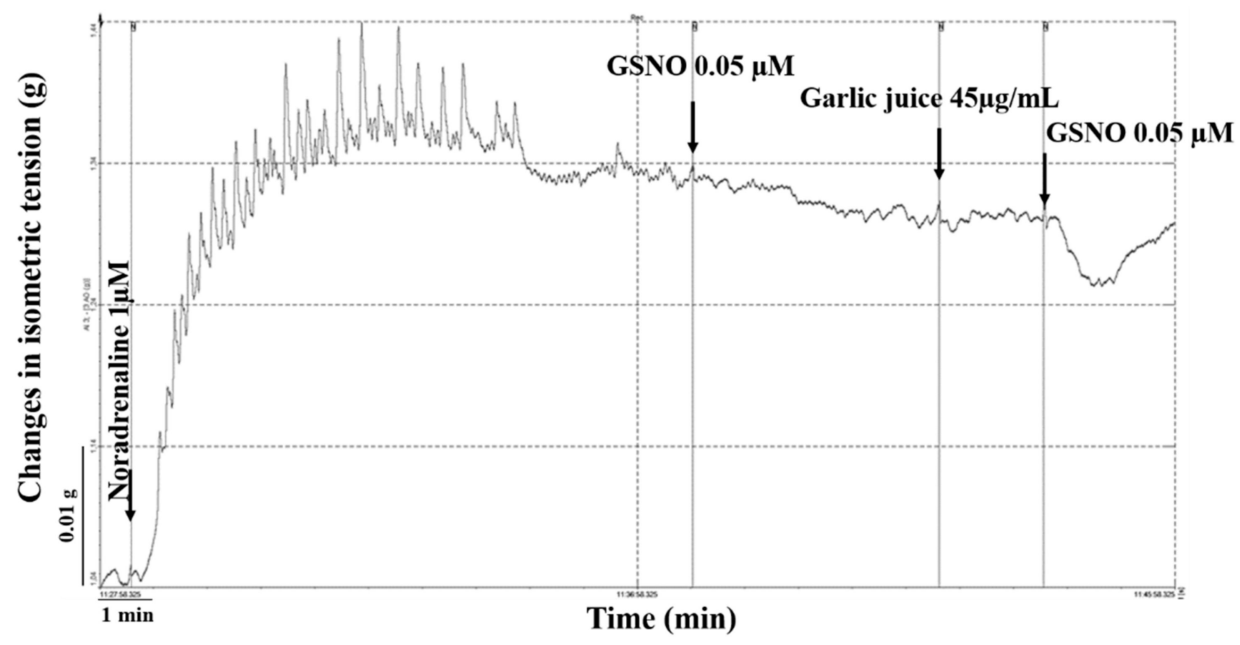

(a)

Figure 2. Cont. 


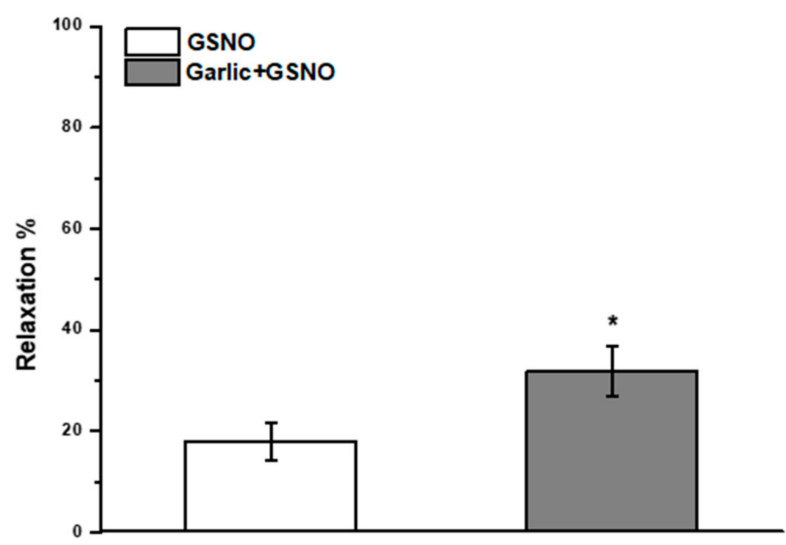

(b)

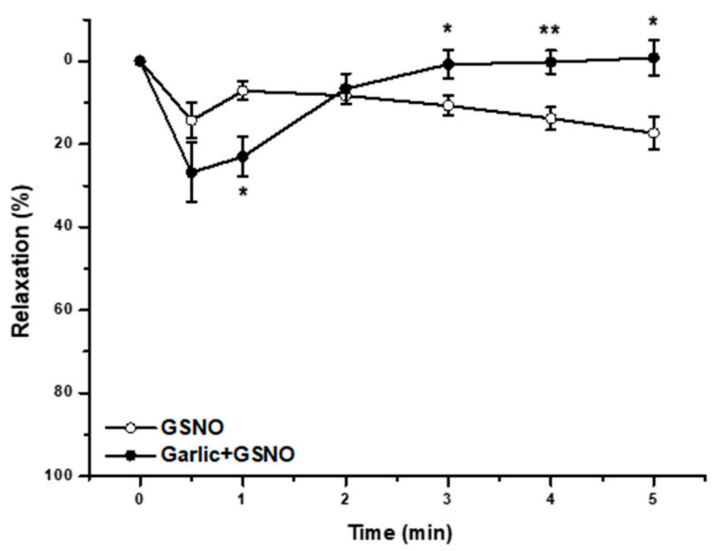

(c)

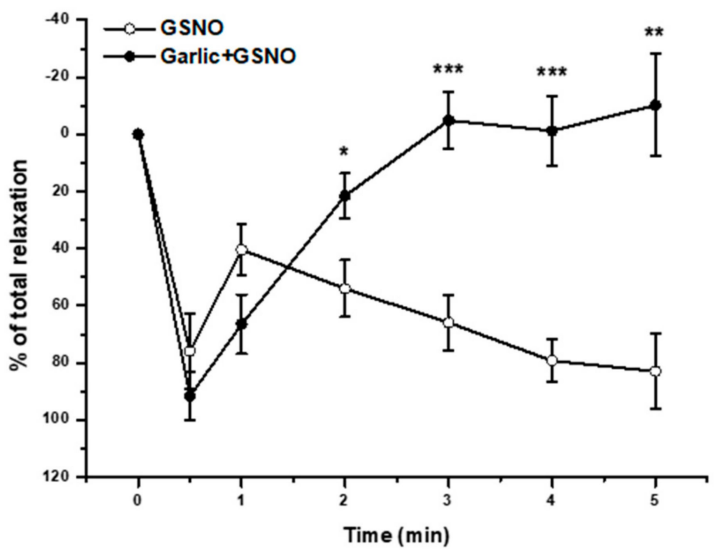

(d)

Figure 2. The comparison of the vasorelaxation induced by S-nitrosoglutathione (GSNO) alone and after incubation with garlic juice. Original record of the incubation with garlic juice (a). The comparison of the maximal relaxation (b) and the absolute (c) as well as the relative (d) relaxation in time induced by GSNO $(0.05 \mu \mathrm{M})$ alone and by GSNO $(0.05 \mu \mathrm{M})$ after incubation of precontracted aortic rings with garlic juice $(45 \mathrm{ug} / \mathrm{mL})(n=9)$. Values are mean \pm S.E.M. ${ }^{*} p<0.05 ;{ }^{* *} p<0.01 ;{ }^{* * *} p<0.001$ with respect to the value of the GSNO response. 


\subsection{Effect of $\mathrm{H}_{2} \mathrm{~S}$-Donor Incubation}

We incubated the noradrenaline-precontracted aortic rings with the $\mathrm{H}_{2} \mathrm{~S}$ donor, $\mathrm{Na}_{2} \mathrm{~S}(40 \mu \mathrm{M}$; $n=8$ ) for $3 \mathrm{~min}$. This concentration of $\mathrm{Na}_{2} \mathrm{~S}$ did not have a significant effect on the arterial tone (Figure 3a). However, it modified the maximal vasorelaxant response of precontracted aortic rings to GSNO $(0.5 \mu \mathrm{M} ; n=8)$. The maximum enriched relaxation was significantly increased after incubation with $\mathrm{Na}_{2} \mathrm{~S}$ compared with the relaxation induced by GSNO alone ( $p<0.05$; Figure $\left.3 b\right)$. The absolute relaxation over time was not changed (Figure $3 \mathrm{c}$ ). Moreover, incubation with $\mathrm{Na}_{2} \mathrm{~S}$ did not affect the speed of the relaxation (Figure 3d).

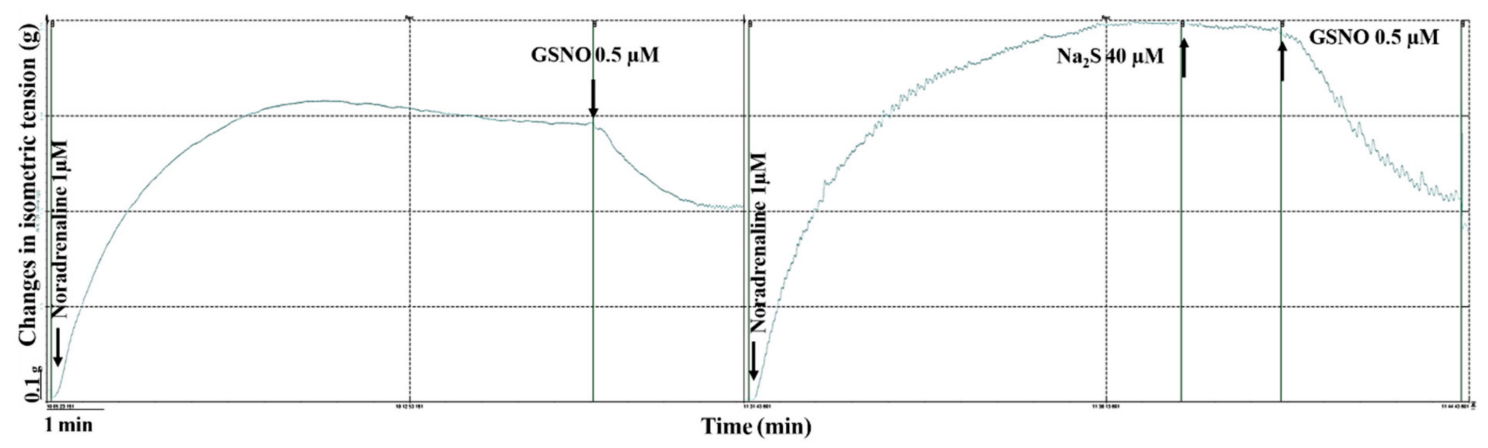

(a)

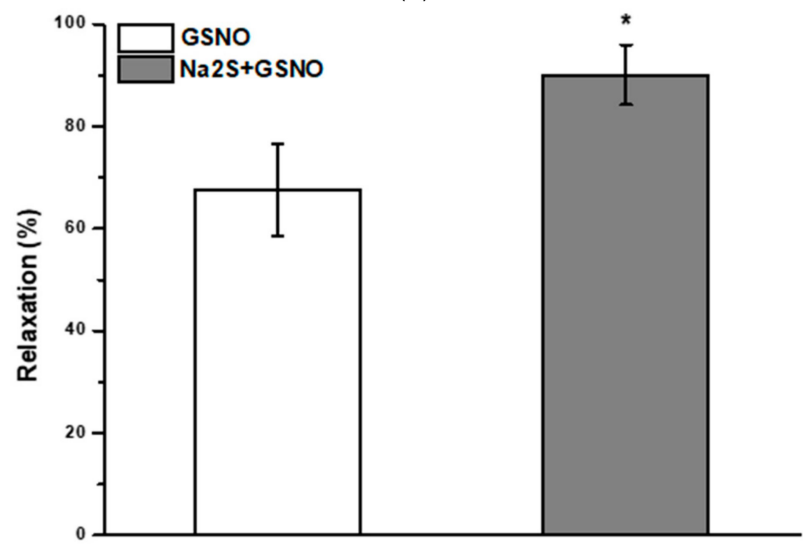

(b)

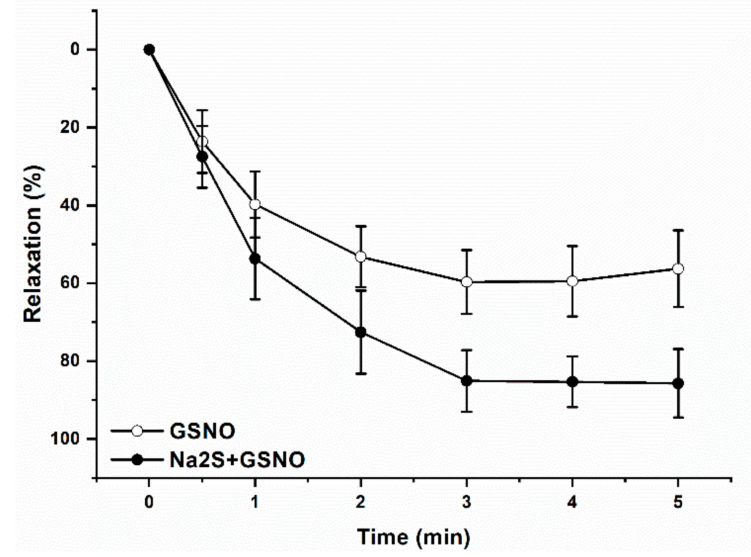

(c)

Figure 3. Cont. 


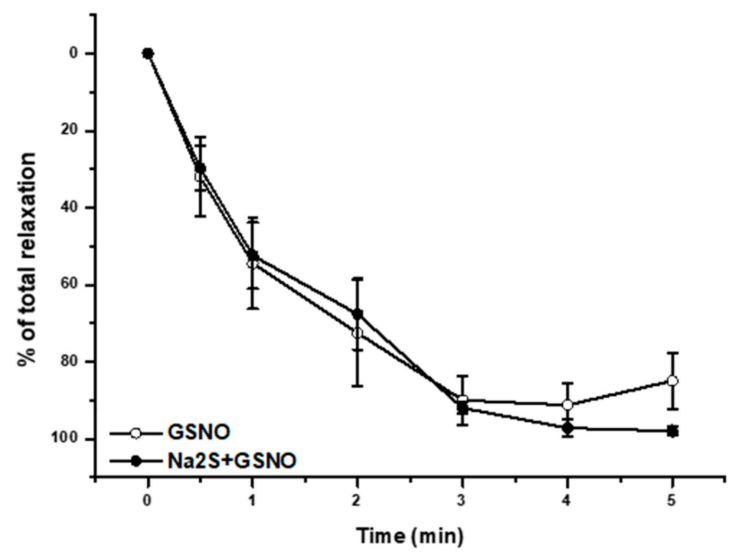

(d)

Figure 3. The comparison of the vasorelaxation induced by GSNO alone and after incubation with $\mathrm{Na}_{2} \mathrm{~S}$. Original record of the incubation with $\mathrm{Na}_{2} \mathrm{~S}(40 \mu \mathrm{M})(\mathbf{a})$. The comparison of the maximal relaxation (b) and the absolute (c) as well as the relative (d) relaxation in time induced by GSNO $(0.5 \mu \mathrm{M})$ alone and by GSNO $(0.5 \mu \mathrm{M})$ after incubation of the precontracted aortic rings with $\mathrm{Na}_{2} \mathrm{~S}(40 \mu \mathrm{M})(n=8)$.

Values are mean \pm S.E.M. ${ }^{*} p<0.05$.

\subsection{Effect of the $\mathrm{H}_{2} \mathrm{~S} / G S N O$ Products}

The $\mathrm{H}_{2} \mathrm{~S} / \mathrm{GSNO}$ products $\left(0.5 \mu \mathrm{M}\right.$ : mixture of $5 \mu \mathrm{M} \mathrm{Na} \mathrm{N}_{2} \mathrm{~S}+0.5 \mu \mathrm{M}$ GSNO; $\left.n=19\right)$ induced a significantly enhanced maximal vasorelaxation compared to GSNO alone $(p<0.001$; Figure $4 \mathrm{a} ; n=19)$. The $\mathrm{H}_{2} \mathrm{~S} / \mathrm{GSNO}$ products $(0.5 \mu \mathrm{M})$ triggered a pronounced absolute vasorelaxation (at the $0.5^{\text {th }}, 1^{\text {st }}$, $2^{\text {nd }}, 3 \mathrm{rd}, 4^{\text {th }}$ and $\left.5^{\text {th }} \mathrm{min}\right)$, followed by a quick return (at the $15^{\text {th }}$ minute) $(p<0.05 ; p<0.01 ; p<0.001$; Figure $4 \mathrm{~b}$ ). The time-dependent relative relaxation was also different at all the measured points: the initiation of relaxation $\left(0.5^{\text {th }}, 1^{\text {st }}\right.$ and $2^{\text {nd }}$ minute), achievement of maximal relaxation $\left(3^{\text {rd }}, 4^{\text {th }}\right.$ and $5^{\text {th }}$ minute) and return $\left(10^{\text {th }}\right.$ and $15^{\text {th }}$ minute) were faster after $\mathrm{H}_{2} \mathrm{~S} / \mathrm{GSNO}$ product application than those after GSNO application alone ( $p<0.01 ; p<0.001$; Figure 4c).

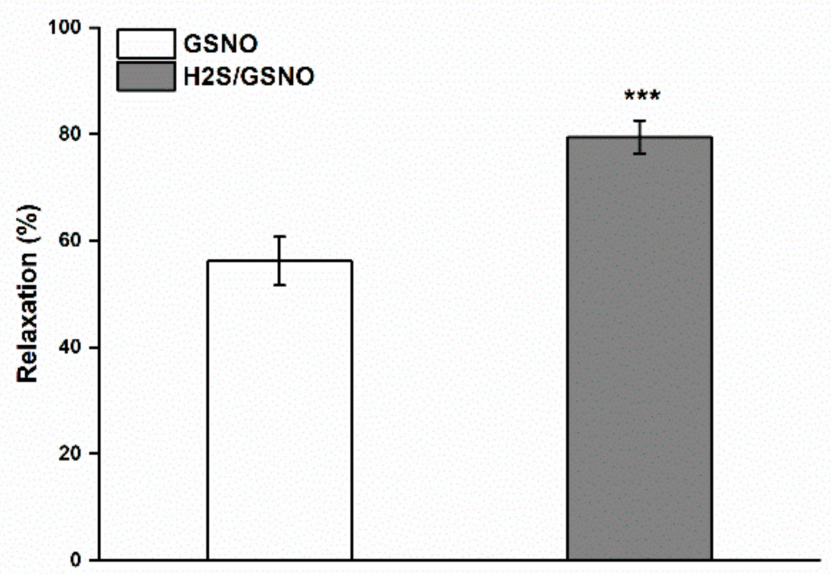

(a)

Figure 4. Cont. 


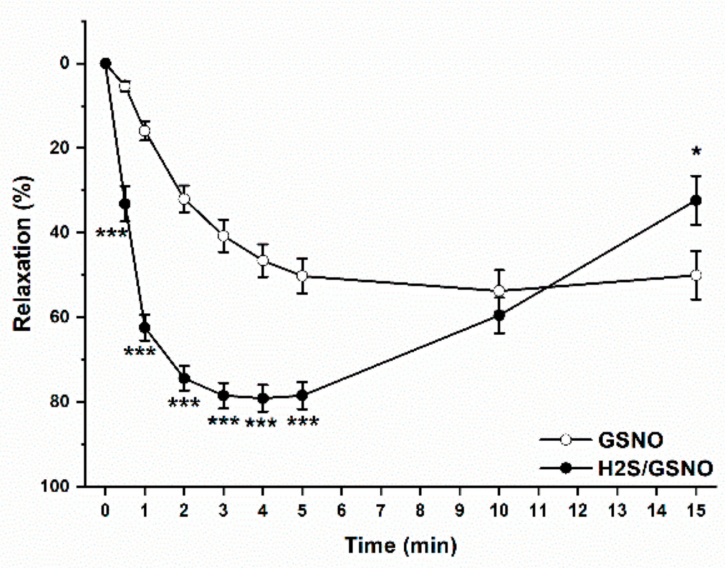

(b)

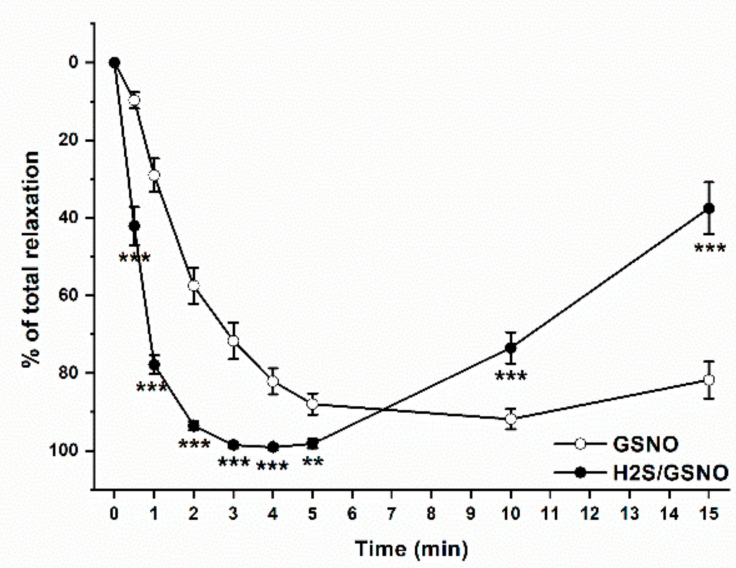

(c)

Figure 4. The comparison of the vasorelaxation induced by GSNO alone and by $\mathrm{H}_{2} \mathrm{~S} / \mathrm{GSNO}$ products. The comparison of the maximal relaxation (a) and the absolute (b) as well as the relative (c) relaxation in time induced by GSNO $(0.5 \mu \mathrm{M})$ alone and by $\mathrm{H}_{2} \mathrm{~S} / \mathrm{GSNO}$ products $(0.5 \mu \mathrm{M})(n=19)$. Values are mean \pm S.E.M. ${ }^{*} p<0.05 ;{ }^{* *} p<0.01{ }^{* * *} p<0.001$ with respect to the value of the GSNO response.

Next, we tried to find out the possible mechanisms of vasorelaxation induced by the $\mathrm{H}_{2} \mathrm{~S} / \mathrm{GSNO}$ products. We tested the involvement of the sGC signaling pathway, the nitroxyl (HNO) and the hyperpolarization in this reaction. Pretreatment with [1H-[1,2,4]oxadiazolo-[4,3-a]quinoxalin-1-one] (10 $\mu \mathrm{M}$; ODQ; $20 \mathrm{~min})$, an inhibitor of sGC, significantly inhibited the vasorelaxation induced by the $\mathrm{H}_{2} \mathrm{~S} / \mathrm{GSNO}$ products $(0.5 \mu \mathrm{M})$ over the entire period $(n=8 ; p<0.01 ; p<0.001$; Figure 5a). Incubation with an HNO scavenger, $N$-acetylcysteine $(1 \mathrm{mM} ; \mathrm{NAC} ; 20 \mathrm{~min})$ did not affect the maximum vasorelaxant effect induced by the $\mathrm{H}_{2} \mathrm{~S} / \mathrm{GSNO}$ products $(n=8$; Figure $5 \mathrm{~b})$. However, NAC incubation changed the character of the response, and influenced the return of vasorelaxation (at the $10^{\text {th }}$ and $15^{\text {th }} \mathrm{min}$ ) when an inhibition was observed $(p<0.05 ; p<0.01)$. To demonstrate the possible effect of hyperpolarization in the vasorelaxation induced by the $\mathrm{H}_{2} \mathrm{~S} / \mathrm{GSNO}$ products, the aortic rings were incubated with a nonspecific $\mathrm{K}^{+}$channel inhibitor, tetraethylammonium chloride (1 mM; TEA; 20 min). TEA incubation had no effect on $\mathrm{H}_{2} \mathrm{~S} / \mathrm{GSNO}$ product-induced vasorelaxation (Figure $5 \mathrm{c}$ ) assuming that hyperpolarization did not belong to the main vasorelaxant mechanisms of vasorelaxation of the $\mathrm{H}_{2} \mathrm{~S} / \mathrm{GSNO}$ products. 


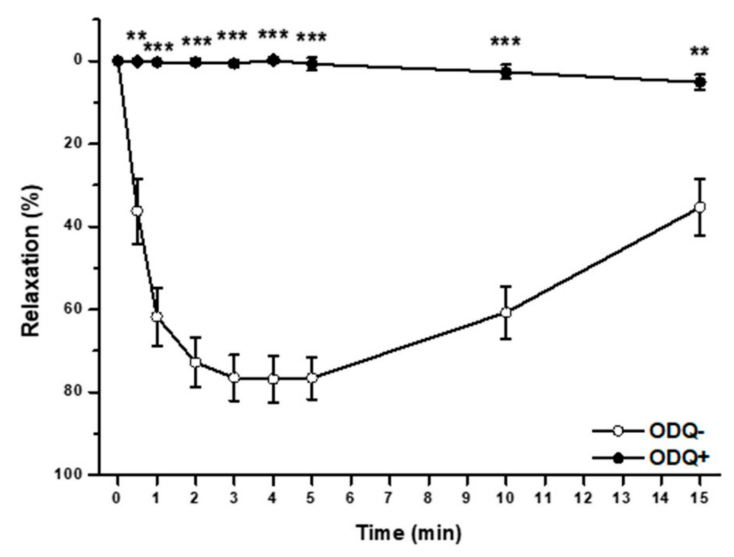

(a)

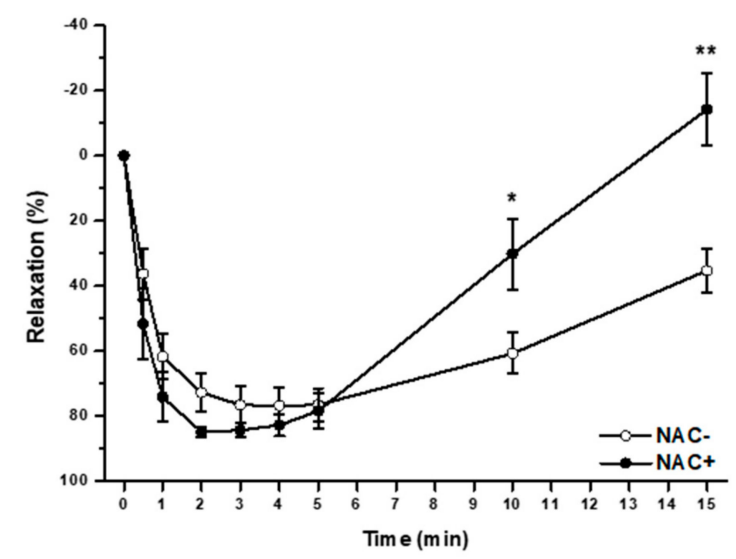

(b)

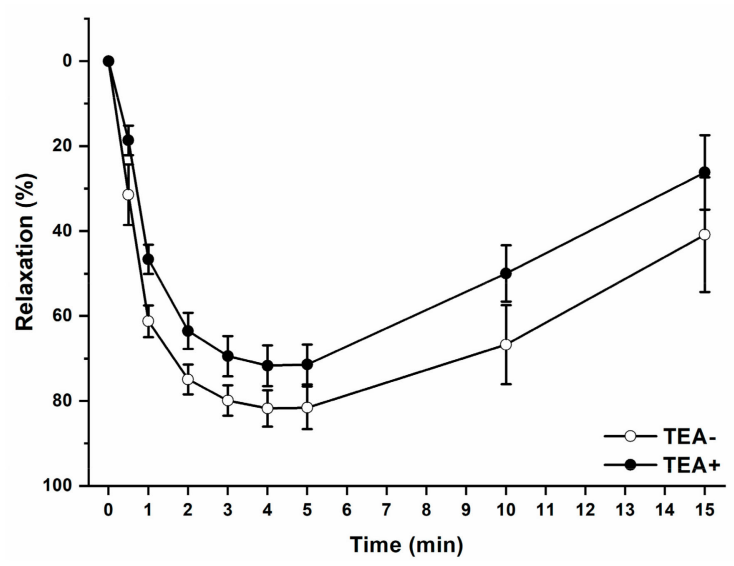

(c)

Figure 5. The possible mechanism of the vasorelaxation induced by $\mathrm{H}_{2} \mathrm{~S} / \mathrm{GSNO}$ products. The comparison of the relaxation ( $\%)$ to $\mathrm{H}_{2} \mathrm{~S} / \mathrm{GSNO}$ products $(0.5 \mu \mathrm{M})$ after soluble guanylyl cyclase inhibitor (ODQ; $10 \mu \mathrm{M} ; \mathbf{a})$, HNO scavenger (NAC; $1 \mathrm{mM} ; \mathbf{b}$ ) and non-specific $\mathrm{K}^{+}$channel inhibitor (TEA, $1 \mathrm{mM}$; c). Values are mean \pm S.E.M. ${ }^{*} p<0.05 ;{ }^{* *} p<0.01$; ${ }^{* * *} p<0.001$ with respect to the value of the $\mathrm{H}_{2} \mathrm{~S} / \mathrm{GSNO}$ products response. 


\section{Discussion}

The main findings of our study are that garlic juice enhances the relaxant effect of exogenous NO donor, GSNO. To the best of our knowledge, we report for the first time that the vasoactive effect of garlic is most likely not evoked by $\mathrm{H}_{2} \mathrm{~S}$ directly but rather by the intermediate reaction products of the $\mathrm{H}_{2} \mathrm{~S}$ and $\mathrm{NO}$ interaction.

The GC-MS analysis showed the presence of sulfur-containing species in the garlic juice, which are assumed to be representatives of garlic bioactive molecules [24]. We need to keep in mind that disruption of garlic cloves leads to the activation of enzymes responsible for the formation of thiosulfinates, among which allicin is considered to be the most important biologically active compound, but it is unstable, and a bunch of degradation compounds forms during garlic processing and handling. Thus, the major organosulfur volatiles as diallyl sulfide, diallyl disulfide and diallyl trisulfide (Figure 1) are formed by the decomposition of allicin and subsequently may play a biological role through $\mathrm{H}_{2} \mathrm{~S}$ release with involvement of thiols [25].

Recent studies have revealed that garlic extract has the ability to lower blood pressure in uncontrolled hypertensives [26] and suppresses the increase of systolic blood pressure with age in spontaneously hypertensive rats [1]. Takashima et al. [23] demonstrated that aged garlic extract affects the vascular endothelium, leading to vasorelaxation through promoting NO production mediated by endothelial NO-synthase. The concentration of garlic juice used in our study had no effect on the precontracted aortic rings but altered the NO donor-induced (S-nitrosogluthatione, GSNO) vasorelaxant response. Maximum GSNO-induced vasorelaxation was significantly increased after incubation with garlic juice; moreover, the time-dependent course of the response was also different in comparison to that of relaxation induced by GSNO alone (Figure $2 \mathrm{a}-\mathrm{d}$ ). This result could indicate a possible interaction of some compounds in garlic juice with GSNO, potentiating the release of NO. Previously it has been demonstrated that garlic extract has high NO-releasing potency expressly depending on $\mathrm{pH}[27]$.

$\mathrm{H}_{2} \mathrm{~S}$ has mostly beneficial effects during oxidative stress by reacting with reactive oxygen and nitrogen species (i.e., hydrogen peroxide $\left(\mathrm{H}_{2} \mathrm{O}_{2}\right)$, superoxide anion radical $\left(\mathrm{O}_{2}{ }^{\bullet-}\right)$, hypochlorite $(\mathrm{HOCl})$, or peroxynitrite $\left(\mathrm{ONOO}^{-}\right)$) [28-31]. Our recent study demonstrates that $\mathrm{H}_{2} \mathrm{~S}$ is not necessarily a typical reducing agent, such as ascorbic acid or tocopherol when employed on their own. We also found that polysulfides and products of $\mathrm{H}_{2} \mathrm{~S}-\mathrm{NO}$ interaction are better superoxide radical $\left(\mathrm{O}_{2}{ }^{\bullet-}\right)$ scavengers than $\mathrm{H}_{2} \mathrm{~S}$, glutathione or vitamin $\mathrm{E}$ derivative, modulate DNA damage and interfere with virus replication; they induce/inhibit apoptosis and modulate the intracellular calcium concentration depending on $\mathrm{H}_{2} \mathrm{O}_{2}$ concentration. Thus, the products of polysulfides/ $\mathrm{NO} / \mathrm{H}_{2} \mathrm{O}_{2}$ interaction may be involved in free radicals signaling, thus modulating oxidative and antioxidative, alternatively cytotoxic biological processes [32].

It has been reported that $\mathrm{H}_{2} \mathrm{~S}$ potentiates the release of $\mathrm{NO}$ from GSNO in a pH-dependent fashion; therefore, we could assume that $\mathrm{H}_{2} \mathrm{~S}$ may be the compound responsible for the extent of GSNO relaxation after incubation with garlic juice [16]. Evidence of the $\mathrm{H}_{2} \mathrm{~S} / \mathrm{GSNO}$ interaction has also been demonstrated by several other studies $[16,21,33]$. Studies on adult normotensive rats suggested that $\mathrm{NO}$ released from GSNO may interact with $\mathrm{H}_{2} \mathrm{~S}$ to form an unknown complex directly in arterial tissue because preincubation of the rat thoracic aorta with a low concentration of $\mathrm{H}_{2} \mathrm{~S}$ subsequently led to heightened GSNO-induced relaxation even after elimination of $\mathrm{H}_{2} \mathrm{~S}$ from the organ bath. The authors assumed that sulfur may create component(s) in the wall of the aortic rings to induce NO release from GSNO [15,34]. We simultaneously incubated the aortic ring with an $\mathrm{H}_{2} \mathrm{~S}$ donor to determine whether $\mathrm{H}_{2} \mathrm{~S}$ mimics the heightened vasorelaxation recorded after incubation with the garlic juice. We incubated precontracted aortic rings with an $\mathrm{H}_{2} \mathrm{~S}$ donor, $\mathrm{Na}_{2} \mathrm{~S}$, alone and followed how it affected GSNO-induced relaxation. Although incubation with $\mathrm{H}_{2} \mathrm{~S}$ increased the maximal achieved relaxation after application of GSNO, the time-dependent characteristic of the response was not altered (Figure 3a-d). According to our results, it seems that the crucial compound in garlic responsible for extending GSNO-induced relaxation is probably not $\mathrm{H}_{2} \mathrm{~S}$ itself. These findings are supported by our previous results reporting 
that the time dependence of NO release initiated by fresh garlic extract was significantly different from the time dependence of $\mathrm{NO}$ release evoked by $\mathrm{Na}_{2} \mathrm{~S}$ [27]. However, we could not exclude the production of $\mathrm{H}_{2} \mathrm{~S}$ as an intermediate reaction product during the chemical reaction with fresh garlic extract. Based on the ability of fresh garlic extract to release NO, it has been suggested at least two possible compounds that could release $\mathrm{NO}$ from $\mathrm{NO}$ donors. As $\mathrm{H}_{2} \mathrm{~S}$ donors, organosulfur compounds in garlic extract release $\mathrm{H}_{2} \mathrm{~S}$ via a relatively slow mechanism that requires the cooperation of endogenous thiols, such as glutathione $[25,35]$. The authors also indicated that $\mathrm{H}_{2} \mathrm{~S}$ was produced by compounds that include sulfane sulfur, such as persulfides and polysulfides, or by $\mathrm{S}^{\circ}$-producing compounds, such as alkyl-cysteine disulfides.

These results suggest that $\mathrm{H}_{2} \mathrm{~S}$ released from organosulfur compounds in garlic extract likely interacts with NO from GSNO, which changes its vasoactive properties. We have previously confirmed that a mixture of both donors relaxes the phenylephrine-precontracted rings of the thoracic aorta and the mesenteric artery in normotensive rats with a more than twofold potency compared with GSNO alone. Additionally, the onset of vasorelaxation of the reaction products was 7-10 times faster compared with that induced by GSNO [21]. In the present study, we also showed that the mixture of GSNO-Na ${ }_{2} S$ products evoked a relaxation of the thoracic aorta of Wistar rats. The time-dependent curve of this reaction was very similar to that of GSNO-induced relaxation after incubation with garlic extract; nevertheless, the curve was significantly higher and faster compared to the effect induced by GSNO alone (Figure $4 \mathrm{a}-\mathrm{c}$ ). Several compounds have been suggested to play a role in mediating the interaction between S-nitrosothiols (RSNO) and $\mathrm{H}_{2} \mathrm{~S}$, altering their bioactive effects: nitroxyl (HNO), thionitrous acid (HSNO), nitrosopersulfide $\left(\mathrm{SSNO}^{-}\right), \mathrm{N}$-nitrosohydroxylamine-N-sulfonate (SULFI/NO) and polysulfides (HSx-) [17-21,36]. Moreover, Cacanyiova et al. [33] studied the renal arteries of spontaneously hypertensive rats and found that the production of specific reaction products was coupled with a unique interaction between $\mathrm{GSNO}$ and $\mathrm{H}_{2} \mathrm{~S}$, as using a different chemical NO donor (DEA NONOate) in the mixture with an $\mathrm{H}_{2} \mathrm{~S}$ donor behaved differently than application of GSNO. Cortese-Krott et al. [16] proposed $\mathrm{SSNO}^{-}$to be a major longer-lived product of the sulfide/RSNOs reaction. These authors demonstrated that under conditions of excess sulfide, $\mathrm{SSNO}^{-}$forms, leading to a higher rate of NO release, which activated sGC more effectively than the starting RSNO by itself. On the other hand, Filipovic et al. [18] and Wedmann et al. [37] considered HNO from sulfide/RSNOs reaction products to be the most extensive bioactive effector. They suggested that although $\mathrm{SSNO}^{-}$ can be produced during the sulfide/RSNOs reaction, their importance is as a generator of HNO. Similarly, Nava et al. [38] suggested that the cross-talk observed between $\mathrm{H}_{2} \mathrm{~S}$ and $\mathrm{NO}$ could be mediated by HSNO and manifested as HNO.

To test the possible signaling pathways involved in the vasorelaxation of $\mathrm{H}_{2} \mathrm{~S} / \mathrm{GSNO}$ reaction products, we used an SGC inhibitor (ODQ), a non-specific potassium-channel inhibitor (TEA) and an HNO scavenger (NAC) (Figure 5a-c). While ODQ significantly inhibited the vasorelaxant effect, TEA had no effect on the $\mathrm{H}_{2} \mathrm{~S} / \mathrm{GSNO}$ products-induced relaxation. Although the pretreatment with NAC did not change the maximal vasorelaxation, the development of the vasorelaxant response over time was significantly inhibited. Thus, it seems that $\mathrm{H}_{2} \mathrm{~S} / \mathrm{GSNO}$ product-induced relaxation is primarily mediated by the activation of sGC and that the hyperpolarization of smooth muscle after potassium-channel activation plays no significant role in this response. $\mathrm{H}_{2} \mathrm{~S}$ donors can evoke vasorelaxation predominantly at concentrations $>100 \mu \mathrm{M}$, and $\mathrm{H}_{2}$ S-induced vascular smooth muscle relaxation is mainly induced through the activation of potassium channels followed by membrane hyperpolarization [39]. Therefore, we can assume that $\mathrm{H}_{2} \mathrm{~S}$ itself probably does not participate in the relaxation induced by $\mathrm{H}_{2} \mathrm{~S} / \mathrm{GSNO}$ reaction products. The involvement of the sGC signaling pathway in $\mathrm{H}_{2} \mathrm{~S} / \mathrm{GSNO}$-induced relaxation has already been demonstrated. Moreover, studies have also shown that a significant portion of $\mathrm{H}_{2} \mathrm{~S} / \mathrm{GSNO}$ vasorelaxation is mediated by an alternative mechanism, which may directly activate sGC without releasing free NO [21]. Moreover, the inhibition of the $\mathrm{H}_{2} \mathrm{~S} / \mathrm{GSNO}$ products-induced vasorelaxation after NAC incubation supports the view that one of the $\mathrm{H}_{2} \mathrm{~S} / \mathrm{GSNO}$ products is $\mathrm{HNO}$ or one/more $\mathrm{H}_{2} \mathrm{~S} / \mathrm{GSNO}$ products are capable of releasing HNO. On the 
other hand, $\mathrm{HNO}$ has a significant effect in only the prolongation of the vasorelaxation of the $\mathrm{H}_{2} \mathrm{~S} / \mathrm{GSNO}$ products (the return of the reaction was faster after the HNO scavenging). According to these findings, $\mathrm{HNO}$ very probably does not represent the crucial vasorelaxant compound of the $\mathrm{H}_{2} \mathrm{~S} / \mathrm{GSNO}$ mixture. These results correlate with our previous results, when we showed that the $\mathrm{H}_{2} \mathrm{~S} / \mathrm{GSNO}$ products evoked similar vasoactive effect with similar mechanisms in the lobar artery isolated from hypertensive patient as well as of the renal artery isolated from spontaneously hypertensive rats [33].

The present study provides original data describing the vasomodulatory mechanisms of garlic juice and attempts to investigate the possible involvement of the nitroso-sulfide signaling pathway in this effect. We confirmed that organosulfur compounds of garlic juice could interact with S-nitrosothiols in a specific way, inducing enhanced vasorelaxation of the rat thoracic aorta. According to our results, we can assume that even if an $\mathrm{H}_{2} \mathrm{~S}$ donor could potentiate $\mathrm{NO}$ release from a NO donor, $\mathrm{H}_{2} \mathrm{~S}$ itself cannot be considered as a crucial bioactive compound of garlic juice. Our results indicate rather the production of new signaling molecules during the GSNO- $\mathrm{H}_{2} \mathrm{~S}$ interaction.

\section{Materials and Methods}

\subsection{Guide for the Use and Care of Laboratory Animals}

All experiments were performed in accordance with institutional guidelines and were approved by the State Veterinary and Food Administration of the Slovak Republic and by an ethics committee according to the European Convention for the Protection of Vertebrate Animals used for Experimental and other Scientific Purposes, Directive 2010/63/EU of the European Parliament. All rats used in this study were born in the accredited breeding establishment of the Institute of Normal and Pathological Physiology, Centre of Experimental Medicine, Slovak Academy of Sciences (INPP CEM SAS), and were housed in groups of 3 animals per cage, each strain separately, under a $12 \mathrm{~h}$ light- $12 \mathrm{~h}$ dark cycle at a constant humidity $(45-65 \%)$ and temperature $\left(20-22{ }^{\circ} \mathrm{C}\right)$ with free access to standard laboratory rat chow and drinking water. The INPP CEM SAS provided veterinary care.

\subsection{Chemicals}

Pieces of garlic weighing $6 \mathrm{~g}$ were pressed through $1.2 \mathrm{~mm}$ diameter pores into $20 \mathrm{~mL}$ of buffer containing, in mM: $160 \mathrm{KCl}, 1 \mathrm{MgCl}_{2}, 0.1$ diethylenetriaminepentaacetic acid (DTPA), and 50 HEPES/TRIS, pH 7.4. The garlic homogenate was vortexed for $1 \mathrm{~min}$ (1800 rev/min), and the juice was extracted by separating it from debris using a Teflon glass homogenizer. Aqueous garlic extract was used fresh or was aliquoted $11 \mathrm{~min}$ after clove pulverization and stored at $-70^{\circ} \mathrm{C}$. Frozen juice was used for several days at a concentration of $130 \mu \mathrm{M} / \mathrm{kg}$ homogenate.

The stock solution of S-nitrosoglutathione (GSNO, $10 \mathrm{mM}$ ) was prepared by dissolving GSNO in buffer: Tris- $\mathrm{HCl}(100 \mathrm{mM})$, DTPA $(0.1 \mathrm{mM}), \mathrm{pH}$ 7.4. The solution was then placed in to a $-80^{\circ} \mathrm{C}$ freezer until use. The concentration of the stock solution was also determined spectrophotometrically using an extinction coefficient of $922 \mathrm{M}^{-1} \mathrm{~cm}^{-1}$ at $335 \mathrm{~nm}$. On the day of the experiment, the stock solution $(30 \mu \mathrm{L})$ was thawed and mixed with a buffer, Tris- $\mathrm{HCl}(200 \mathrm{mM})$; the $\mathrm{pH}$ was adjusted to 7.4; and the mixture was kept in sealed vials. GSNO was applied to isolated vessels at concentrations of 0.05 and $0.5 \mu \mathrm{M}$.

$\mathrm{Na}_{2} \mathrm{~S} \bullet 9 \mathrm{H}_{2} \mathrm{O}$ was used as an $\mathrm{H}_{2} \mathrm{~S}$ donor, which dissociates in water into $\mathrm{Na}^{+}$and $\mathrm{S}^{2-}$ and reacts with $\mathrm{H}^{+}$to yield $\mathrm{HS}^{-}$and $\mathrm{H}_{2} \mathrm{~S}$. We use the term $\mathrm{Na}_{2} \mathrm{~S}$ to encompass the total mixture of $\mathrm{H}_{2} \mathrm{~S}, \mathrm{HS}^{-}$ and $\mathrm{S}^{2-}$. The stock solution of $\mathrm{Na}_{2} \mathrm{~S}(100 \mathrm{mM})$ was prepared by dissolving it in ultrapure deionized water $(\geq 18 \mathrm{M} \Omega . \mathrm{cm})$ (Millipore, Darmstadt, Germany). The stock solution was stored in a $-80{ }^{\circ} \mathrm{C}$ freezer. On the day of the experiment, the stock solution $(100 \mu \mathrm{L})$ was thawed and mixed with a buffer, Tris- $\mathrm{HCl}(200 \mathrm{mM}), \mathrm{pH}$ 7.4. The solution was always prepared fresh before the experiment and kept in sealed vials with a minimal headspace and used immediately at concentrations of $40 \mu \mathrm{M}$. 
The products of the $\mathrm{Na}_{2} \mathrm{~S}-\mathrm{GSNO}$ interaction ( $\mathrm{H}_{2} \mathrm{~S} / \mathrm{GSNO}$ products) were generated at a 10:1 ratio (molar excess of $\mathrm{Na}_{2} \mathrm{~S}$ over GSNO). In short, we mixed $0.5 \mathrm{mM} \mathrm{GSNO}$ with $5 \mathrm{mM} \mathrm{Na}_{2} \mathrm{~S}$ at $21 \pm 2{ }^{\circ} \mathrm{C}$ and waited $3 \mathrm{~min}$ until the reaction products were completely formed.

\subsection{GC-MS Analysis}

GC-MS analysis of garlic juice was made by Agilent Technologies 7890A with mass spectrometer (Agilent Technologies 5975C, Santa Clara, CA, USA). This instrument was operated in the electron impact (EI) mode set at electron energy $70 \mathrm{eV}$ with a scan range from 33 to 330. Separation was carried out on GC-column HP-5 (Agilent Technologies, Santa Clara, CA, USA) with dimensions $30 \mathrm{~m}$ length $\times 0.25 \mathrm{~mm}$ diameter, and a film thickness of $0.25 \mu \mathrm{m}$ Helium with purity $99.9995 \%$ was used as the carrier gas with a flow rate of $1.7 \mathrm{~mL} / \mathrm{min}$ on the column head. The temperature of the injector was set at $280{ }^{\circ} \mathrm{C}$. The temperature program started at $40^{\circ} \mathrm{C}$ for $0 \mathrm{~min}$. Subsequently, the temperature was increased with a gradient of $3^{\circ} \mathrm{C} / \mathrm{min}$ to a final temperature of $170{ }^{\circ} \mathrm{C}$ for $2 \mathrm{~min}$.

The samples were prepared using liquid-liquid extraction method. $1 \mathrm{~mL}$ of solvent chloroform with HPLC purity was used for $2 \mathrm{~mL}$ of sample. After this, $1 \mu \mathrm{L}$ of the chloroform extract was injected by autosampler (Agilent Technologies G4513A, Santa Clara, CA, USA) into the instrument with a split ratio of 20:1.

Identification of compounds was performed by comparing the spectra with the NIST 14 library and by comparing retention times.

\subsection{Measurement of the Vasoactive Response and Experimental Protocols}

The thoracic aorta of male Wistar rats (16 weeks old) was isolated after a brief $\mathrm{CO}_{2}$ anesthetization and decapitation of the animals. The $5 \mathrm{~mm}$ long rings were vertically fixed between two stainless wire triangles in a $20 \mathrm{~mL}$ incubation organ bath with Krebs solution (in mM: $118 \mathrm{NaCl}, 5 \mathrm{KCl}, 25 \mathrm{NaHCO}_{3}$, $1.2 \mathrm{MgSO}_{4}, 1.2 \mathrm{KH}_{2} \mathrm{PO}_{4}, 2.5 \mathrm{CaCl}_{2}, 11$ glucose, $0.032 \mathrm{CaNa}_{2}$ EDTA). The solution was oxygenated with $95 \% \mathrm{O}_{2}$ and $5 \% \mathrm{CO}_{2}$ and kept at $37^{\circ} \mathrm{C}$. The upper triangles were connected to isometric tension sensors (FSG-01, MDE, Budapest, Hungary), and changes in tension were registered by an AD converter NI USB-6221 (National Instruments, Austin, TX, USA and MDE, Budapest, Hungary). Changes in isometric tension were registered by the DEWEsoft (Dewetron, Prague, Czech Republic) and SPEL Advanced Kymograph (MDE, Budapest, Hungary) software. A resting tension of $1 \mathrm{~g}$ was applied to each ring and maintained throughout a 45 to $60 \mathrm{~min}$ equilibration period until stress relaxation no longer occurred.

Briefly, to test the effect of garlic juice on GSNO-induced $(0.05 \mu \mathrm{M})$ relaxation, noradrenaline-precontracted $(1 \mu \mathrm{M})$ aortic rings were incubated with garlic juice for $3 \mathrm{~min}$. The effect of the $\mathrm{H}_{2} \mathrm{~S}$ donor $\left(\mathrm{Na}_{2} \mathrm{~S}\right)$ was evaluated in a similar way: after $3 \mathrm{~min}, \mathrm{Na}_{2} \mathrm{~S}$ pretreatment GSNO $(0.5 \mu \mathrm{M})$ was applied. Then, the mixture of $\mathrm{Na}_{2} \mathrm{~S}$ and GSNO $\left(5 \mu \mathrm{M} \mathrm{Na}{ }_{2} \mathrm{~S}+0.5 \mu \mathrm{M}\right.$ GSNO; see also above) was applied on the noradrenaline-precontracted rings. To confirm the involvement of the sGC signaling pathway in the relaxation effect of the $\mathrm{H}_{2} \mathrm{~S} / \mathrm{GSNO}$ products, an sGC inhibitor, $1 H$-[1,2,4] oxadiazolo[4,3-a]quinoxalin-1-one (ODQ, $10 \mu \mathrm{M})$, was applied $20 \mathrm{~min}$ before the addition of the contractile agonist. To test the assumption that the vasorelaxation of the mixture was mediated by the release of nitroxyl (HNO), experiments were also carried out after 20 min of pretreatment with an HNO scavenger, $N$-acetylcysteine (NAC, $1 \mathrm{mM}$ ). A nonspecific $\mathrm{K}^{+}$channel inhibitor, tetraethylammonium chloride (TEA, $1 \mathrm{mM}$ ), was pretreated for $20 \mathrm{~min}$ in an organ bath to evaluate the participation of $\mathrm{K}^{+}$ channels in the vasorelaxation of the $\mathrm{H}_{2} \mathrm{~S} / \mathrm{GSNO}$ products.

First, the absolute maximal and time-dependent vasorelaxant effects of all the compounds were expressed as a percentage of the noradrenaline-induced precontraction. Second, the relative time-dependent vasorelaxant effect (the speed of vasorelaxation) of all the compounds was expressed as a percentage of the maximal relaxation. The values of the arterial tone were assessed at the $0.5^{\text {th }}, 1^{\text {st }}$, $2^{\text {nd }}, 3 \mathrm{rd}, 4^{\text {th }}, 5^{\text {th }}, 10^{\text {th }}$ and $15^{\text {th }}$ min after drug application. 


\subsection{Statistical Analysis}

For the statistical evaluation of differences between groups, one-way analysis of variance (ANOVA) was used, followed by the Bonferroni post-hoc test. The maximum of the enriched vasorelaxation was evaluated using paired $t$-test. Differences between means were considered significant at $p<0.05$.

\section{Conclusions}

The present study provides original data describing the vasomodulatory mechanisms of garlic juice and attempts to investigate the possible involvement of the nitroso-sulfide signaling pathway in this effect. We confirmed that organosulfur compounds of garlic juice could interact with $S$-nitrosothiols in a specific way, inducing enhanced vasorelaxation of the rat thoracic aorta. According to our results, we can assume that even if an $\mathrm{H}_{2} \mathrm{~S}$ donor could potentiate $\mathrm{NO}$ release from a NO donor, $\mathrm{H}_{2} \mathrm{~S}$ itself cannot be considered as a crucial bioactive compound of garlic juice. Our results indicate the possible production of new signaling molecules during the GSNO- $\mathrm{H}_{2} \mathrm{~S}$ interaction.

Author Contributions: Conceptualization, S.C.; methodology, A.B., M.G., A.M., S.G., J.C.; software, S.C.; validation, S.C.; formal analysis, A.B.; investigation, A.B., M.G., A.M., S.G, J.C.; resources, S.C.; data curation, A.B.; writing—original draft preparation, A.B.; writing—review and editing, A.B., S.C., M.G., A.M.; visualization, A.B.; supervision, S.C.; project administration, S.C.; funding acquisition, S.C, M.G., A.B. All authors have read and agreed to the published version of the manuscript.

Funding: This research was funded by projects of the Slovak Research and Development Agency (APVV-15-0565, APVV-15-0371) and the Scientific Grant Agency of The Ministry of Education, Science, Research and Sport of the Slovak Republic (VEGA 2/0111/19, VEGA 2/0079/19).

Conflicts of Interest: The authors declare no conflict of interest.

\section{References}

1. Harauma, A.; Moriguchi, T. Aged garlic extract improves blood pressure in spontaneously hypertensive rats more safely than raw garlic. J. Nutr. 2006, 136, 769S-773S. [CrossRef] [PubMed]

2. Hayat, S.; Cheng, Z.; Ahmad, H.; Ali, M.; Chen, X.; Wang, M. Garlic, from Remedy to Stimulant: Evaluation of Antifungal Potential Reveals Diversity in Phytoalexin Allicin Content among Garlic Cultivars; Allicin Containing Aqueous Garlic Extracts Trigger Antioxidants in Cucumber. Front. Plant. Sci. 2016, 7, 1235. [CrossRef] [PubMed]

3. Lee, H.S.; Lim, W.C.; Lee, S.J.; Lee, S.H.; Lee, J.H.; Cho, H.Y. Antiobesity Effect of Garlic Extract Fermented by Lactobacillus plantarum BL2 in Diet-Induced Obese Mice. J. Med. Food 2016, 19, 823-829. [CrossRef] [PubMed]

4. Percival, S.S. Aged Garlic Extract Modifies Human Immunity. J. Nutr. 2016, 146, 433S-436S. [CrossRef]

5. Yun, H.M.; Ban, J.O.; Park, K.R.; Lee, C.K.; Jeong, H.S.; Han, S.B.; Hong, J.T. Potential therapeutic effects of functionally active compounds isolated from garlic. Pharmacol. Ther. 2014, 142, 183-195. [CrossRef]

6. Münchberg, U.; Anwar, A.; Mecklenburg, S.; Jacob, C. Polysulfides as biologically active ingredients of garlic. Org. Biomol. Chem. 2007, 21, 1505-1518. [CrossRef]

7. Kwak, J.S.; Kim, J.Y.; Paek, J.E.; Lee, Y.J.; Kim, H.R.; Park, D.S.; Kwon, O. Garlic powder intake and cardiovascular risk factors: A meta-analysis of randomized controlled clinical trials. Nutr. Res. Pract. 2014, 8, 644-654. [CrossRef]

8. Cerella, C.; Dicato, M.; Jacob, C.; Diederich, M. Chemical properties and mechanisms determining the anti-cancer action of garlic-derived organic sulfur compounds. Anticancer Agents. Med. Chem. 2011, 11, 267-271. [CrossRef]

9. Jacob, C.; Anwar, A. Sulfides in Allium Vegetables. In Chemoprevention of Cancer and DNA Damage by Dietary Factors; Knasmüller, S., DeMarini, D.M., Johnson, I., Gerhäuser, C., Eds.; Wiley-Blackwell: Hoboken, NJ, USA, 2009; pp. 663-684.

10. Shouk, R.; Abdou, A.; Shetty, K.; Sarkar, D.; Eid, A.H. Mechanisms underlying the antihypertensive effects of garlic bioactives. Nutr. Res. 2014, 34, 106-115. [CrossRef] 
11. Liu, Y.H.; Lu, M.; Hu, L.F.; Wong, P.T.; Webb, D.G.; Bian, J.S. Hydrogen sulphide in the mammalian cardiovascular system. Antioxid. Redox. Signal. 2012, 17, 141-185. [CrossRef]

12. Cebova, M.; Kosutova, M.; Pechanova, O. Cardiovascular effects of gasotransmitter donors. Physiol. Res. 2016, 65, S291-S307. [PubMed]

13. Palinkas, Z.; Furtmuller, P.G.; Nagy, A.; Jakopitsch, C.; Pirker, K.F.; Magierowski, M.; Jasnos, K.; Wallace, J.L.; Obinger, C.; Nagy, P. Interactions of hydrogen sulfide with myeloperoxidase. Br. J. Pharmacol. 2015, 172, 1516-1532. [CrossRef] [PubMed]

14. Li, Q.; Lancaster, J.R. Chemical foundations of hydrogen sulfide biology. Nitric Oxide 2013, 35, 21-34. [CrossRef] [PubMed]

15. Ng, E.S.; Cheng, Z.J.; Ellis, A.; Ding, H.; Jiang, Y.; Li, Y.; Hollenberg, M.D.; Triggle, C.R. Nitrosothiol stores in vascular tissue: Modulation by ultraviolet light, acetylcholine and ionomycin. Eur. J. Pharmacol. 2007, 560, 183-192. [CrossRef]

16. Ondrias, K.; Stasko, A.; Cacanyiova, S.; Sulova, Z.; Krizanova, O.; Kristek, F.; Malekova, L.; Knezl, V.; Breier, A. H(2)S and HS(-) donor NaHS releases nitric oxide from nitrosothiols, metal nitrosyl complex, brain homogenate and murine L1210 leukaemia cells. Pflugers Arch. 2008, 457, 271-279. [CrossRef]

17. Yong, Q.C.; Hu, L.F.; Wang, S.; Huang, D.; Bian, J.S. Hydrogen sulfide interacts with nitric oxide in the heart: Possible involvement of nitroxyl. Cardiovasc. Res. 2010, 88, 482-491. [CrossRef] [PubMed]

18. Filipovic, M.R.; Miljkovic, J.; Nauser, T.; Royzen, M.; Klos, K.; Shubina, T.; Koppenol, W.H.; Lippard, S.J.; Ivanovic-Burmazovic, I. Chemical characterization of the smallest S-nitrosothiol, HSNO; cellular cross-talk of H2S and S-nitrosothiols. J. Am. Chem. Soc. 2012, 134, 12016-12027. [CrossRef]

19. Eberhardt, M.; Dux, M.; Namer, B.; Miljkovic, J.; Cordasic, N.; Will, C.; Kichko, T.I.; de la Roche, J.; Fischer, M.; Suarez, S.A.; et al. $\mathrm{H}_{2} \mathrm{~S}$ and $\mathrm{NO}$ cooperatively regulate vascular tone by activating a neuroendocrine HNO-TRPA1-CGRP signalling pathway. Nat. Commun. 2014, 5, 4381. [CrossRef]

20. Cortese-Krott, M.M.; Fernandez, B.O.; Santos, J.L.; Mergia, E.; Grman, M.; Nagy, P.; Kelm, M.; Butler, A.; Feelisch, M. Nitrosopersulfide (SSNO(-)) accounts for sustained NO bioactivity of S-nitrosothiols following reaction with sulfide. Redox Biol. 2014, 2, 234-244. [CrossRef]

21. Berenyiova, A.; Grman, M.; Mijuskovic, A.; Stasko, A.; Misak, A.; Nagy, P.; Ondriasova, E.; Cacanyiova, S.; Brezova, V.; Feelisch, M.; et al. The reaction products of sulfide and S-nitrosoglutathione are potent vasorelaxants. Nitric Oxide 2015, 46, 123-130. [CrossRef]

22. Kimura, H. Physiological Roles of Hydrogen Sulfide and Polysulfides. Handb. Exp. Pharmacol. 2015, $230,61-81$. [PubMed]

23. Takashima, M.; Kanamori, Y.; Kodera, Y.; Morihara, N.; Tamura, K. Aged garlic extract exerts endothelium-dependent vasorelaxant effect on rat aorta by increasing nitric oxide production. Phytomedicine 2017, 24, 56-61. [CrossRef]

24. Martins, N.; Petropoulos, S.; Ferreira, I.C. Chemical composition and bioactive compounds of garlic (Allium sativum L.) as affected by pre- and post-harvest conditions: A review. Food. Chem. 2016, 211, 41-50. [CrossRef] [PubMed]

25. Grman, M.; Nasim, M.J.; Leontiev, R.; Misak, A.; Jakusova, V.; Ondrias, K.; Jacob, C. Inorganic Reactive Sulfur-Nitrogen Species: Intricate Release Mechanisms or Cacophony in Yellow, Blue and Red? Antioxidants 2017, 6, 1-16. [CrossRef]

26. Ried, K.; Frank, O.R.; Stocks, N.P. Aged garlic extract reduces blood pressure in hypertensives: A dose-response trial. Eur. J. Clin. Nutr. 2013, 67, 64-70. [CrossRef]

27. Grman, M.; Misak, A.; Cacanyiova, S.; Kristek, F.; Tomaskova, Z.; Bertova, A.; Ondrias, K. The aqueous garlic, onion and leek extracts release nitric oxide from S-nitrosoglutathione and prolong relaxation of aortic rings. Gen. Physiol. Biophys. 2011, 30, 396-402. [CrossRef]

28. Misak, A.; Grman, M.; Bacova, Z.; Rezuchova, I.; Hudecova, S.; Ondriasova, E.; Krizanova, O.; Brezova, V.; Chovanec, M.; Ondrias, K. Polysulfides and products of H2S/S-nitrosoglutathione in comparison to H2S, glutathione and antioxidant Trolox are potent scavengers of superoxide anion radical and produce hydroxyl radical by decomposition of $\mathrm{H} 2 \mathrm{O} 2$. Nitric Oxide 2018, 76, 136-151. [CrossRef]

29. Stasko, A.; Brezová, V.; Zalibera, M.; Biskupic, S.; Ondrias, K. Electron transfer: A primary step in the reactions of sodium hydrosulphide, an H2S/HS- donor. Free Rad. Res. 2009, 43, 581-593. [CrossRef] 
30. Whiteman, M.; Armstrong, J.S.; Chu, S.H.; Jia-Ling, S.; Wong, B.S.; Cheng, N.S.; Halliwell, B.; Moore, P.K. The novel neuromodulator hydrogen sulfide: An endogenous peroxynitrite 'scavenger'? J. Neurochem. 2004, 90, 765-768. [CrossRef]

31. Whiteman, M.; Cheung, N.S.; Zhu, Y.-Z.; Chu, S.H.; Sian, J.L.; Wong, B.S.; Armstrong, J.S.; Moore, P.K. Hydrogen sulphide: A novel inhibitor of hypochlorous acid-mediated oxidative damage in the brain? Biochem. Biophys. Res. Comm. 2005, 326, 794-798. [CrossRef]

32. Grman, M.; Misak, A.; Kurakova, L.; Brezova, V.; Cacanyiova, S.; Berenyiova, A.; Balis, P.; Tomasova, L.; Kharma, A.; Domínguez-Álvarez, E.; et al. Products of Sulfide/Selenite Interaction Possess Antioxidant Properties, Scavenge Superoxide-Derived Radicals, React with DNA, and Modulate Blood Pressure and Tension of Isolated Thoracic Aorta. Oxid. Med. Cell. Longev. 2019, 2019, 9847650. [CrossRef] [PubMed]

33. Cacanyiova, S.; Berenyiova, A.; Balis, P.; Kristek, F.; Grman, M.; Ondrias, K.; Breza, J.; Breza, J., Jr. Nitroso-sulfide coupled signaling triggers specific vasoactive effects in the intrarenal arteries of patients with arterial hypertension. J. Physiol. Pharmacol. 2017, 68, 527-538. [PubMed]

34. Bertova, A.; Cacanyiova, S.; Kristek, F.; Krizanova, O.; Ondrias, K.; Tomaskova, Z. The hypothesis of the main role of H2S in coupled sulphide-nitroso signalling pathway. Gen. Physiol. Biophys. 2010, 29, 402-410. [CrossRef] [PubMed]

35. Bhuiyan, A.I.; Papajani, V.T.; Paci, M.; Melino, S. Glutathione-garlic sulfur conjugates: Slow hydrogen sulfide releasing agents for therapeutic applications. Molecules 2015, 20, 1731-1750. [CrossRef] [PubMed]

36. Hess, D.T.; Stamler, J.S. Regulation by S-nitrosylation of protein post-translational modification. J. Biol. Chem. 2012, 287, 4411-4418. [CrossRef]

37. Wedmann, R.; Zahl, A.; Shubina, T.E.; Durr, M.; Heinemann, F.W.; Bugenhagen, B.E.; Burger, P.; Ivanovic-Burmazovic, I.; Filipovic, M.R. Does perthionitrite $(\mathrm{SSNO}(-))$ account for sustained bioactivity of NO? A (bio)chemical characterization. Inorg. Chem. 2015, 54, 9367-9380. [CrossRef]

38. Nava, M.; Martin-Drumel, M.A.; Lopez, C.A.; Crabtree, K.N.; Womack, C.C.; Nguyen, T.L.; Thorwirth, S.; Cummins, C.C.; Stanton, J.F.; McCarthy, M.C. Spontaneous and Selective Formation of HSNO, a Crucial Intermediate Linking H2S and Nitroso Chemistries. J. Am. Chem. Soc. 2016, 138, 11441-11444. [CrossRef]

39. Zhao, W.; Zhang, J.; Lu, Y.; Wang, R. The vasorelaxant effect of $\mathrm{H}_{2} \mathrm{~S}$ as a novel endogenous gaseous K(ATP) channel opener. EMBO J. 2001, 20, 6008-6016. [CrossRef]

Sample Availability: Not available.

(C) 2020 by the authors. Licensee MDPI, Basel, Switzerland. This article is an open access article distributed under the terms and conditions of the Creative Commons Attribution (CC BY) license (http://creativecommons.org/licenses/by/4.0/). 